\title{
Supersaturation, dehydration, and denitrification in Arctic cirrus
}

\author{
B. Kärcher \\ Deutsches Zentrum für Luft- und Raumfahrt (DLR), Institut für Physik der Atmosphäre (IPA), Oberpfaffenhofen, Germany \\ Received: 1 February 2005 - Published in Atmos. Chem. Phys. Discuss.: 22 March 2005 \\ Revised: 6 June 2005 - Accepted: 17 June 2005 - Published: 20 July 2005
}

\begin{abstract}
A polar cirrus case study is discussed with the help of a one-dimensional model with explicit aerosol and ice microphysics. It is demonstrated that continuous cooling of air in regions with small amounts of ice and slow ice deposition rates of water vapor drives significant in-cloud supersaturations over ice, with potentially important consequences for heterogeneous halogen activation. Radiatively important cloud properties such as ice crystal size distributions are investigated, showing the presence of high number concentrations of small crystals in the cloud top region at the tropopause, broad but highly variable size spectra in the cloud interior, and mostly large crystals at the cloud base. It is found that weakly forced Arctic cirrostratus are highly efficient at dehydrating upper tropospheric air. Estimating nitric acid uptake in cirrus with an unprecedented treatment of diffusion-limited trapping in growing ice crystals suggests that such clouds could also denitrify upper tropospheric air masses efficiently, but a closer comparison to suitable observations is needed to draw a definite conclusion on this point. It is also shown that low temperatures, high ice supersaturations, and the absence of ice above but close to the cloud top region cause efficient uptake of nitric acid in background aerosol particles.
\end{abstract}

\section{Introduction}

Unraveling the role clouds and associated climatic feedbacks play in modulating the Greenhouse warming in the Arctic is a key element in many global climate studies (Curry et al., 1996). Airborne measurements of total water suggest that dehydration by cirrus clouds at high latitudes was responsible for the observed wintertime asymmetry of upper tropospheric water concentrations between the Northern and Southern hemispheres (Kelly et al., 1991). Owing to the low

Correspondence to: B. Kärcher

(bernd.kaercher@dlr.de) temperatures prevailing in the winter upper troposphere and lower stratosphere, cirrus clouds form frequently at high latitudes, and their occurrence is often tied to synoptic weather systems (Del Guasta et al., 1994, 1998; Masuda et al., 2000; Petzold et al., 2000; Reichardt et al., 2002; Pfister et al., 2003). Clear observational evidence exists for ice clouds in the layer between the local tropopause and the hygropause at polar latitudes (Kärcher and Solomon, 1999; Lelieveld et al., 1999). Little is known about Arctic cirrus clouds due to their difficult accessibility and the resulting paucity of observations, although these clouds are capable of exerting a noticeable radiative impact, drying the upper troposphere, activating heterogeneous chemistry affecting ozone, redistributing trace gases, and seeding lower mixed-phase clouds via vertical redistribution of ice nuclei.

\subsection{Radiation and chemistry issues}

The ice crystals in high Arctic clouds absorb upwelling infrared radiation and thereby heat the tropopause region and isolate the polar troposphere from cooling. At the same time, these clouds exert a counteracting solar-albedo effect by reflecting more sunlight back to space. Both effects are not well quantified. Data from the International Satellite Cloud Climatology Project (ISCCP, D2 dataset) reveal global annual mean high cloud (above $440 \mathrm{hPa}$ ) occurrence frequencies of $19.6 \%$ at $60^{\circ} \mathrm{N}$ (Rossow and Schiffer, 1999). This figure is a lower limit because thin clouds with optical depths below $0.1-0.3$ are not detected. Accurate satellite remote sensing of Arctic clouds is severely hampered by the little contrast between cloud and the underlying reflecting snow or ice surface, the relatively small cloud optical depths, the existence of low-level fog and haze, and the partial absence of sunlight (Curry et al., 2000). Improvements of retrieval algorithms require knowledge of ice crystal size and shapes and the amount of cloud ice all of which are hardly known for Arctic cirrus. 
Arctic cirrus clouds are known to dehydrate and possibly denitrify upper tropospheric air masses. Cirrus have been suspected to be responsible for the observed dryness of air in the Arctic winter (Murphy et al., 1990). In situ measurements of water $\left(\mathrm{H}_{2} \mathrm{O}\right)$ close to the winter Arctic tropopause have shown that the formation of cirrus and subsequent sedimentation of ice crystals may dry the air on the time scale of a few hours (Schiller et al., 1999). More recent in situ measurements in the same region quantified the condensed phase water and ice crystal size distributions, yielding evidence for the presence of large (size exceeding $20 \mu \mathrm{m}$ ) ice cyrstals in Arctic cirrus (Hallar et al., 2004). Such large crystals are capable of redistributing water (and other trace gases attached to them) and heterogeneous ice nuclei (if the crystals formed on them) efficiently by rapid gravitational settling.

A combination of trace gas and trajectory analyses based on aircraft measurements have shown a significant potential for cirrus formation well above $(\sim 3 \mathrm{~km})$ the Arctic tropopause from midwinter to early spring. Cirrus form because of the simultaneous occurrence of low temperatures $(<210 \mathrm{~K})$ and the enhancement of $\mathrm{H}_{2} \mathrm{O}$ mixing ratios above average stratospheric levels ( $>4-6$ ppmv) by rapid troposphere-to-stratosphere mixing (Pfister et al., 2003). In the Arctic tropopause region and below, the same analyses reveal the frequent occurrence of ice (super-)saturation at low $\mathrm{H}_{2} \mathrm{O}$ mixing ratios ( $5 \mathrm{ppmv}$ ) caused by synoptic storms. These weather systems lift air parcels originally located poleward of the tropospheric jet upward and poleward and trigger cloud formation and dehydration by rapid and strong cooling.

Ozone concentrations have declined at midlatitudes in the northern hemisphere lowermost stratosphere and tropopause region, with mean decadal trends peaking between $-7 \%$ and $-12 \%$ at $100-200 \mathrm{hPa}$ in the winter and spring seasons (Logan et al., 1999). Both changes in transport and heterogeneous chemisty have been invoked to explain these large negative trends, but their relative contributions are uncertain.

Tracer transport studies have shown that gases released north of $50^{\circ} \mathrm{N}$ between $150-300 \mathrm{hPa}$ could be efficiently mixed into the midlatitude regions where ozone is observed to decline (Rogers et al., 2002). Chemistry-transport models predict the activation of significant quantities of chlorine in the presence of cirrus clouds (Solomon et al., 1997). Chlorine activation on cold aerosol droplets and ice particles, subsequent catalytic destruction of ozone, and export of chemically processed air to midlatitudes helps to explain the observed ozone trends at midlatitudes, provided cirrus occur frequently at high latitudes up to a few kilometers above the tropopause (see above) and the heterogeneous chemical reactions known to occur on polar stratospheric cloud particles similarly enhance reactive chlorine in the presence of liquid aerosols and cirrus clouds (Borrmann et al., 1996).

The presence of reactive halogenes (e.g., in the form of chlorine oxide, $\mathrm{ClO}$ ) does not necessarily correlate with the presence of cirrus clouds at the same location, because the chemical activation times of $\mathrm{ClO}$ are short and perturbations to reactive chlorine can persist for many weeks, while cirrus clouds have a limited life time and may be transported in different air masses. Recent observational evidence for the presence of enhanced levels of $\mathrm{ClO}$ near the winter Arctic tropopause has been reported by Thornton et al. (2003). Measured mixing ratios of $\mathrm{ClO}$ of 15-20 pptv exceeded typical values found in airborne measurements in relatively dry conditions by at least a factor of 10 (Smith et al., 2001), constituting an effective loss process for ozone. More recent measurements at a similar time and location in the Arctic confirm these data, showing even higher levels of $\mathrm{ClO}$ between 20-40 pptv slightly above the tropopause, in one instant within a cirrus cloud (F. Stroh, personal communication, 2005). Even in the absence of cloud, halogen activation proceeds very rapidly on background aerosols (see below) composed of $\mathrm{H}_{2} \mathrm{O}$, sulfuric acid $\left(\mathrm{H}_{2} \mathrm{SO}_{4}\right)$, and nitric acid $\left(\mathrm{HNO}_{3}\right)$, at low temperatures $(<205 \mathrm{~K})$ above ice saturation without freezing (Meilinger et al., 2001).

\subsection{Nitric acid phase partitioning in cirrus clouds}

Uptake of $\mathrm{HNO}_{3}$ on or in ice has been reported in numerous laboratory and field measurements (Popp et al., 2004, and references therein). Given the variety of conditions under which $\mathrm{HNO}_{3}$-ice interaction may take place in the atmosphere (wide ranges of temperatures, $\mathrm{HNO}_{3}$ partial pressures, and cirrus properties) and uncertainties in theoretical descriptions of the uptake process, it remains largely unclear if cirrus-induced denitrification is relevant globally and which cirrus type is most effective in vertically redistributing $\mathrm{HNO}_{3}$. Besides providing an overview of the temporal and spatial development of radiatively important parameters such as ice crystal size distributions and examining the possibility for ice supersaturation occurring within and dehydration caused by polar cirrus, this served as another motivation to conduct the present study.

Measurements of $\mathrm{HNO}_{3}$ concentrations and other parameters have revealed that liquid ternary aerosols composed of $\mathrm{H}_{2} \mathrm{O}, \mathrm{HNO}_{3}$, and $\mathrm{H}_{2} \mathrm{SO}_{4}$ are present in the Arctic tropopause region (Irie et al., 2004). These aerosols, commonly denoted as supercooled ternary solution (STS) particles, freeze homogeneously to form cirrus clouds at high relative humidities over ice in the same way they serve as nuclei for polar stratospheric ice clouds. Besides being taken up by aerosol particles, $\mathrm{HNO}_{3}$ partitions in the ice phase in the presence of cirrus clouds. A model analysis of the associated nonequilibrium phase partitioning of $\mathrm{HNO}_{3}$, as presented below, has not yet been performed.

Airborne measurements of $\mathrm{HNO}_{3}$ contained in cirrus cloud particles have frequently been expressed in terms of an equilibrium ice surface coverage and fitted to various isotherms as a function of the $\mathrm{HNO}_{3}$ partial pressure and air temperature. A dissociative Langmuir isotherm can be used to fit the uptake data as a function of the partial pressure but fails to provide a reasonable fit as a function of temperature 
(Popp et al., 2004). More importantly, local equilibrium concepts neglect the trapping of $\mathrm{HNO}_{3}$ in the ice crystal volume during growth as well as possible kinetic limitations of uptake and thus are incapable of adequately describing the considerable variability in observed $\mathrm{HNO}_{3}$ content in cirrus ice crystals.

The large scatter and the less than perfect agreement with equilibrium uptake models suggests that ice phase $\mathrm{HNO}_{3}$ is not in equilibrium with its gas phase reservoir, which led Kärcher and Basko (2004) to develop a model for trace gas trapping in growing ice crystals. Trapping integrates the uptake over the entire life cycle of individual ice crystals and cannot simply be correlated to instantaneous variables. This description of uptake combines surface kinetic processes with diffusion-limited trapping of $\mathrm{HNO}_{3}$ along with condensing $\mathrm{H}_{2} \mathrm{O}$ vapor; it is thus physically more plausible than assuming ice equilibrium and calculating the amount of particle $\mathrm{HNO}_{3}$ by model isotherms.

\subsection{Model case study}

Accurate modeling of cirrus clouds and trace gas-ice interactions is of central importance for chemistry-climate prediction and weather forecasts. In this work, the one-dimensional (1-D) vertical, cloud-resolving model APSCm-1-D is presented and applied to an observed Arctic cirrostratus cloud (Reichardt et al., 2002). The simulation is idealized, but it is partly based on information from nearby radiosondes and the results are consistent with the observed, general synopticscale cloud development (see Sect. 3.1).

The 1-D-version has been developed on the basis of the detailed microphysical model APSC (Advanced Particle Simulation Code) (Kärcher, 2003) to simulate vertical advection, size-dependent aerosol particle growth and evaporation, trace gas trapping in ice, homogeneous freezing and heterogeneous ice nucleation, and individual ice crystal growth, sublimation, and sedimentation. Some features such as tracking of individual ice crystals and the treatment of particle water uptake and homogeneous freezing are shared by the model developed by Jensen et al. (2005a). The cloud type has been chosen as the basis for the present model study because of its long life time (at least $7 \mathrm{~h}$ ) and large vertical extent (more than $5 \mathrm{~km}$ ). Together with low air temperatures, these factors potentially favor the partitioning of $\mathrm{HNO}_{3}$ in the ice phase and efficient vertical redistribution of $\mathrm{HNO}_{3}$, and the continuous forcing produces significant supersaturation over ice.

The present simulations combining a cirrus cloudresolving model with a model of trace gas trapping and gasaerosol microphysics are unprecedented. A detailed study of the phase partitioning of $\mathrm{H}_{2} \mathrm{O}$ and $\mathrm{HNO}_{3}$ and associated dehydration and denitrification effects is presented, yielding important insights into the physical processes involved and pointing toward the key issues needed to better understand and predict these processes in future observations and models.
The basic physics of the numerical model is summarized in Sect. 2, in particular the novel features of the APSCm1-D such as vertical transport and the tracking of height and size of many individual ice crystals. Numerical schemes used to solve microphysical equations and explicit expressions for nucleation rate coefficients, vapor fluxes, gas solubilities, and terminal fall speeds are compiled in Kärcher (2003). Results are presented and discussed in Sect. 3 and the conclusions are given in Sect. 4.

\section{Model description}

\subsection{Vertical advection}

Air temperature $T$ and pressure $p$, potential temperature $\theta$, number density of air molecules $c$, as well as volume mixing ratios $\chi_{w}\left(\mathrm{H}_{2} \mathrm{O}\right)$ and $\chi_{n}\left(\mathrm{HNO}_{3}\right)$, aerosol particle number density, and number density of solute $\left(\mathrm{H}_{2} \mathrm{SO}_{4}\right.$ and $\left.\mathrm{HNO}_{3}\right)$ and $\mathrm{H}_{2} \mathrm{O}$ in the aerosol particles are discretized over an altitude (z-)grid. All variables except $p, T$, and $c$, which are computed diagnostically, are advected as volume mixing ratios $\chi$, using a prescribed vertical wind field $w$ that causes adiabatic cooling and serves as the key cloud-forcing agent:

$$
\frac{\partial(\chi c)}{\partial t}+\frac{\partial(w \chi c)}{\partial z}=0 .
$$

Vertical turbulent diffusion is not included.

Advection, aerosol, and ice particle processes are operator-split in the code. The time step is chosen such that the ice saturation ratio $S_{i}$ (usually the most critical and fastest varying parameter) does not vary more than $0.1-1 \%$, but it is also ascertained that crystals do not fall across two altitude bins within a time step and that the Courant-Friedrichs-Levy criterion is not violated.

The sharp gradients and small features in the vertical profiles of relative humidity and other variables in cirrus clouds require the use of a numerical scheme preserving local maxima or minima as accurately as possible. To transport gas and particle volume mixing ratios, a fast yet accurate, monotonic, positive definite, and mass-conserving tracer advection scheme is employed (Walcek, 2000). A $z$-grid is used with a spatial resolution small enough to resolve the rapid homogeneous freezing events that take place in the top cloud layers. The grid spacing $\Delta z$ is obtained from prescribing the minimum and maximum altitude of the vertical domain and the number of altitude bins.

The advection sequence is computed as follows. First, the initial profiles $T(z), \theta(z), S_{i}(z)$, and $\chi_{n}(z)$ are prescribed, along with the vertical wind field $w(z, t)$. The initial pressure profile follows from $p(z)=p_{0}[T(z) / \theta(z)]^{1 / \kappa}$, where $\kappa=2 / 7$ and $p_{0}=1000 \mathrm{hPa}$. The gas phase water mixing ratio $\chi_{w}(z)$ then follows from $S_{i}, T$, and $p$.

Second, $\theta$ is advected in the first time step, and a new pressure profile is obtained with the help of the hydrostatic 
balance $\partial p / \partial z=-g p /(R T)$, where $g$ is the gravitational acceleration and $R$ is the ideal gas constant. Combining this equation with $\theta=T\left(p_{0} / p\right)^{\kappa}$ yields

$$
\frac{\partial \Pi}{\partial z}=-\frac{\Gamma}{\theta}, \quad \Pi=\left(\frac{p}{p_{0}}\right)^{\kappa},
$$

from which $p(\theta)$ follows by integration:

$$
\left[\frac{p(z, t)}{p_{0}}\right]^{\kappa}=\left[\frac{p\left(z_{*}\right)}{p_{0}}\right]^{\kappa}-\Gamma \int_{z_{*}}^{z} \frac{d z}{\theta(z, t)} .
$$

In Eqs. (2) and (3), $\Gamma=g \kappa / R$ is the dry adiabatic lapse rate. Equation (3) is solved by trapezoidal integration. At the fixed reference level $z_{*}$, the initial value $p\left(z_{*}\right)$ is kept constant. A value of $z_{*}$ located in the middle portion of the cloud minimizes the impact of the pressure perturbations in the simulation.

The third step consists of calculating a new temperature profile from the updated $p$ and $\theta$ fields via $T(z, t)=\theta(z, t)\left[p(z, t) / p_{0}\right]^{\kappa}$, and a new air density profile from the ideal gas law $c(z, t)=p(z, t) /\left[k_{B} T(z, t)\right]$, with Boltzmann's constant $k_{B}$. Finally, gas, aerosol number, and aerosol solute and liquid water mixing ratios in each size bin are advected using the updated $c$ field.

\subsection{Aerosol growth, trace gas uptake, and freezing}

Background aerosol particle number concentrations and those of $\mathrm{H}_{2} \mathrm{O}, \mathrm{HNO}_{3}$, and $\mathrm{H}_{2} \mathrm{SO}_{4}$ (per unit volume of air) contained in these particles are discretized over radius bins in each altitude bin. While $\mathrm{H}_{2} \mathrm{SO}_{4}$ is treated as an involatile species in the STS particles, the amount of volatile material is allowed to change kinetically according to condensation and evaporation processes, mainly dictated by the evolution of $T$ (determining the gas solubility in the droplets) and the availability of the molecules in the gas phase.

The exact sizes of the liquid particles are computed by summing up volatile and (constant) nonvolatile contributions to the total particle volume. This Lagrangian approach is free of numerical diffusion. Total mass is exactly conserved between the gas and aerosol phase in each altitude bin. Aerosol particles are not allowed to sediment owing to their small (sub- $\mu \mathrm{m})$ sizes.

The production of ice crystals relies on the water-activitybased homogeneous freezing model for supercooled aerosols (Koop et al., 2000). The STS particles commence to freeze above $S_{i}$ values of 1.5 , depending on $T$ and on the local water activity in each droplet size bin, which is explicitly calculated to allow effects of non-equilibrium aerosol composition to be taken into account. Although the APSCm-1-D allows to study the effects of heterogeneous ice nuclei on cloud formation and development, heterogeneous ice nucleation is not considered in this work.

During freezing of a liquid droplet, solute may be expelled to the surface and may even escape to the gas phase. It is assumed that the complete amount of $\mathrm{HNO}_{3}$ (and $\mathrm{H}_{2} \mathrm{SO}_{4}$ ) residing in the droplets prior to freezing is retained in the ice crystals, but a sensitivity study will examine the effects of changing the retention coefficient upon the $\mathrm{HNO}_{3}$ phase partitioning. Of course, $\mathrm{HNO}_{3}$ dissolved in liquid droplets may evaporate in non-freezing droplets if $S_{i}$ is reduced after ice formation.

\subsection{Growth and sedimentation of ice crystals}

The growth of ice crystals occurs via deposition of water vapor from the gas phase, using a similar diffusional growth law as for liquid aerosols but including the effects of habit and ventilation. Ice particles are hexagonal columns with an aspect ratio of 3 for diameters $>25 \mu \mathrm{m}$ and spheres for smaller sizes. Ventilation enhances sublimation and evaporation rates for large $(>50 \mu \mathrm{m})$ crystals. The ice vapor pressure recommended by Murphy and Koop (2005) is used. Nitric acid uptake does not affect the crystal size owing to the low molar ratio of $\mathrm{HNO}_{3}$ to $\mathrm{H}_{2} \mathrm{O}\left(<10^{-4}\right)$, but the amount of $\mathrm{HNO}_{3}$ contained in individual ice crystals is tracked in the code. The ice crystals sediment owing to gravitational acceleration; their individual locations are obtained by integrating the difference between their size- and habit-dependent terminal fall speed and the local vertical wind over time.

To calculate ice crystal growth, a standard expression for the diffusional growth law (Eq. (15) in Kärcher, 2003) is applied together with a fixed ice mass deposition coefficient of 0.5 (Haynes et al., 1992). Lowering this value would lead to more ice crystals while an increase would have little effect on the results. A fixed value for the deposition coefficient is a simplification. It is possible that real deposition coefficients to be used in conjunction with more sophisticated growth models could show very sensitive dependences on supersaturation. However, such growth models valid for small ice crystals, low temperatures, and high supersaturations are not yet available (Nelson, 2005). On the other hand, the present approach is capable of explaining atmospheric observations in many cases (e.g., Haag et al., 2003a,b; Jensen and Pfister, 2004; Jensen et al., 2005a).

The nucleation, growth, and sedimentation of ice crystals is computed on a particle-by-particle basis (particle-in-cell code), whereby the laws describing depositional growth and combined vertical advection and sedimentation are solved for each individual crystal. The altitude and size where each ice crystal forms serve as the initial conditions to solve these laws, which are integrated with a simple Euler forward scheme. The variables $z, T, p, \chi_{w}, \chi_{n}$ required to compute the vapor and sedimentation fluxes are linearly interpolated to the exact locations of each ice crystal. This method permits the exact conservation of $\mathrm{H}_{2} \mathrm{O}$ and $\mathrm{HNO}_{3}$ between the gas phase and the ice crystals and eliminates any numerical diffusion during growth or fall. If an ice crystal evaporates below its initial size, it is removed from the calculation.

Ice particles are added in each time step in each altitude bin according to the aerosol freezing or ice nucleation rates. 
Liquid particles produce ice particles at their exact size at the point of freezing. The altitude at which ice particles form is randomized within the respective altitude bin.

In order to keep the code efficient, each simulation particle is associated with $\mathcal{N}$ physical ice crystals. A lower limit concentration $n_{*}$ is prescribed which determines the number $\mathcal{N}$ of individual ice crystals generated in the simulation. If $n_{i}$ crystals nucleate per $\mathrm{cm}^{3}$ of air in a given altitude bin per time step, $\mathcal{N}=n_{i} / n_{*}$. The value of $n_{*}$ is a compromise between a good statistical representation of the crystal size distrubtions and the available computational resources.

\subsection{Nitric acid-ice interaction}

The interaction of gaseous $\mathrm{HNO}_{3}$ with ice is simulated using a novel uptake model that allows diffusion-limited trapping of molecules to compete with surface kinetic processes, depending on the relative magnitude of the time of adsorption and the ice crystal growth rate (Kärcher and Basko, 2004).

Experimental evidence exists for the fact that growing ice surfaces lead to enhanced uptake of $\mathrm{HCl}$ (Abbatt et al., 1992; Huthwelker, 1999). Very recently, evidence was found for significantly enhanced uptake of $\mathrm{HNO}_{3}$ by growing relative to static ice films (J. Abbatt and M. Ullerstam, personal communication, 2005). These new laboratory measurements clearly support the main feature of the trapping model, namely that trace gases can effectively be taken up in growing ice particles even at low supersaturations.

The number of $\mathrm{HNO}_{3}$ molecules taken up per unit time by growing ice particles in the APSCm-1-D is given by

$$
\frac{d N_{n}}{d t}=4 \pi r_{i} D_{n} \kappa_{i} \phi_{i} n_{n} \epsilon\left(r_{i}, \dot{r}_{i}, \alpha_{n}, \beta_{n}, k, d\right),
$$

where $r_{i}$ is the effective spherical radius of the ice crystals, $D_{n}$ is the diffusion coefficient of $\mathrm{HNO}_{3}$ molecules in air, $\kappa_{i}$ is the capacitance factor, $\phi_{i}$ is the ventilation factor, $n_{n}=\chi_{n} c$ is the molecular concentration of $\mathrm{HNO}_{3}$ in the gas phase, and $\epsilon$ is the trapping efficiency. Contrary to equilibrium adsorption isotherms, the amount of trapped molecules in a cloud is a non-local quantity, depending on the history of individual ice crystals. This renders a detailed comparison with airborne observations difficult.

The trapping efficiency depends on the individual ice particle growth rate $\dot{r}_{i}$, the deposition coefficient $\alpha_{n}=0.3$ (Hanson, 1992) for $\mathrm{HNO}_{3}$ molecules impinging on the ice surface, and the escape rate $k$ of $\mathrm{HNO}_{3}$ molecules from the ice surface. The second parameter $d$ is tied to the existence of a surface layer at the moving air-ice interface. It is not discussed here further. Finally, $\epsilon$ contains a size-dependent factor $\beta_{n}=\left[1+4 D_{n} \kappa_{i} /\left(\alpha_{n} u_{n} r_{i}\right)\right]^{-1}\left(u_{n}\right.$ is the $\mathrm{HNO}_{3}$ molecular thermal speed) interpolating between the diffusion and kinetic flow regimes.

In the simplest approach, $k$ is interpreted as a desorption rate in the form $\alpha_{n} \omega \exp \left[-Q /\left(k_{B} T\right)\right]$. As a baseline value for the latent heat of adsorption on ice, $Q$, a value of
$10.5 \mathrm{kcal} \mathrm{mol}^{-1}$ is used (Bartels-Rausch et al., 2002); $Q$ is regarded as a fit parameter, as its correct magnitude depends on the choice of the exponential prefactor $\omega$ (taken to be $10^{13} \mathrm{~s}^{-1}$ ). The trapping model requires independent validation. The parameters $k$ and $d$ in the trapping model are poorly constrained and need to be fixed by measurements of gas uptake in growing ice films, as proposed by Kärcher and Basko (2004, their Sect. 5 for more details). Uncertainties arising from the above choice of $Q$ will be addressed in Sect. 3.4.

There exist two limiting cases of trapping. The key parameter $k d / \dot{r}_{i}$ describes the effectiveness of escape of molecules from the ice surface versus ice particle growth. In the limit $k d \gg \dot{r}_{i}$, trapping is controlled by the kinetics at the ice surface, which determines the concentration of trace gas molecules that are subsequently buried by comparatively slowly growing ice layers. Equation (4) takes the form

$\frac{d N_{n}}{d t} \simeq 4 \pi r_{i}^{2} n_{\mathrm{eq}} \dot{r}_{i}$,

where $n_{\mathrm{eq}}$ is the equilibrium concentration determined by the balance between the adsorptive flux $n_{n} \alpha_{n} u_{n} / 4$ and the escape (desorption) flux $n_{\mathrm{eq}} k d$. The difference between these two fluxes enters the trapping model as part of a boundary condition at the moving air-ice interface, and is essentially equivalent to a linear (i.e., unsaturated) adsorption isotherm. When $k d \ll \dot{r}_{i}$, trapping is entirely controlled by the rate of diffusion of the $\mathrm{HNO}_{3}$ molecules through the air toward the ice particle, yielding

$\frac{d N_{n}}{d t} \simeq 4 \pi r_{i} D_{n} \kappa_{i} \phi_{i} n_{n} \beta_{n}$.

In this limit, trapping does not depend on the surface processes.

For evaporating ice crystals, the flux of $\mathrm{HNO}_{3}$ molecules leaving each ice crystal is set proportional to the $\mathrm{H}_{2} \mathrm{O}$ flux times the molar ratio of $\mathrm{HNO}_{3}$ and $\mathrm{H}_{2} \mathrm{O}$ in the crystal.

Recent measurements in subtropical cirrus have suggested that nitric acid trihydrate (NAT) might block active growth sites at the surfaces of cirrus ice crystals below $205 \mathrm{~K}$, leading to a perturbed steady-state between $\mathrm{H}_{2} \mathrm{O}$ vapor and ice accompanied by a persistent in-cloud supersaturation (Gao et al., 2004). As the detailed mechanism by which the ice crystal growth properties are changed by NAT is currently not known, the potential for this effect to occur in polar cirrus is not investigated here.

\section{Results and discussion}

\subsection{Observation and initialization}

Reichardt et al. (2002) report observations of a long-lived cirrostratus cloud system detected by lidar over Kiruna, Sweden, in 1997. Its general synoptic-scale development has 


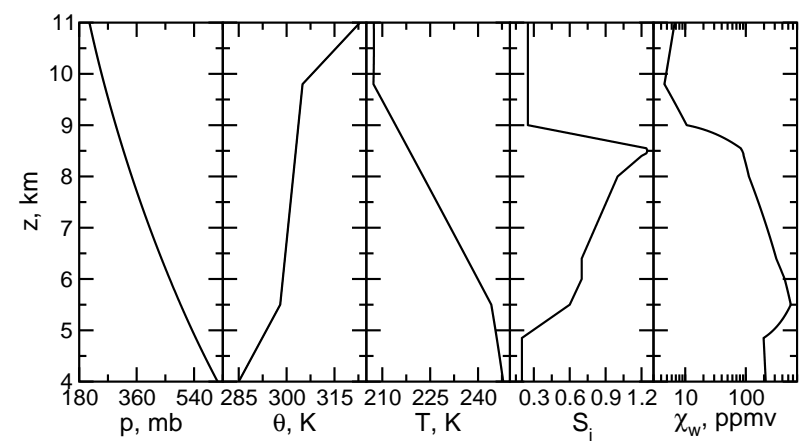

Fig. 1. Prescribed vertical profiles of potential temperature $\theta$, air temperature $T$, and ice saturation ratio $S_{i}$, and inferred profiles of air pressure $p$ and $\mathrm{H}_{2} \mathrm{O}$ gas volume mixing ratio $\chi_{w}$ used to initialize the $7 \mathrm{~h}$ simulation describing the formation (via homogeneous freezing) and evolution of an Arctic cirrostratus cloud. The initial $\mathrm{HNO}_{3}$ mixing ratio (not shown) is set constant, $\chi_{n}=1 \mathrm{ppbv}$.

been studied numerically, with a focus on nucleation pathways (Lin et al., 2005). The foci of the two complementary model studies are thus substantially different from each other.

As described in more detail by Lin et al. (2005), the cloud system was associated with a strong northwesterly jet stream and a surface warm front. While the cloud drifted across the measurement site, the lidar backscatter data show that its top was lifted from $8.5 \mathrm{~km}$ to more than $10 \mathrm{~km}$ within 7 hours at an almost constant rate. Values for the updraft speed in the range $4-6 \mathrm{~cm} \mathrm{~s}^{-1}$ can be estimated from the observed cloud top heights.

Figure 1 presents the initial vertical profiles of $\theta, T$, and $S_{i}$ (R.-F. Lin and J. Reichardt, personal communication, 2004), along with the derived pressure and $\mathrm{H}_{2} \mathrm{O}$ gas mixing ratio profiles. To advect the species and drive the formation of the cloud, a spatially uniform vertical wind speed of $w=5 \mathrm{~cm} \mathrm{~s}^{-1}$ is prescribed throughout the simulation which extends over $7 \mathrm{~h}$.

The initial profiles are based on radiosonde data, taken $250 \mathrm{~km}$ downwind of Kiruna and 2 hours after the cloud formed. The $S_{i}$ profile has been tuned by Lin et al. (2005) together with the imposed vertical ascent rate such that the large-scale cloud development could be reproduced. It is possible that processes controlling the small-scale development of the cloud (waves, turbulence, latent heat release) influence its simulated properties. Uncertainties arising from small-scale processes unresolved in the present simulations will be discussed in following sections.

The APSC $m$-1-D uses a vertical domain extending from 4 to $11 \mathrm{~km}$, divided into 2100 bins, i.e., $\Delta z=3.3 \mathrm{~m}$. The pressure reference altitude is $z_{*}=8.5 \mathrm{~km}$. The time step is fixed to $2 \mathrm{~s}$. The minimum number of ice crystals resolved by the code is $n_{*}=5 \times 10^{-5} \mathrm{~cm}^{-3}$. The maximum number of simulation particles is about 160000 , with $\sim 3.5$ physical ice crystals per simulation particle.
The number of radius bins over which the lognormal aerosol number and component size distributions are discretized is 25 , starting at a radius of $5 \mathrm{~nm}$. The bins increase geometrically in size with a bin volume ratio of 2.25 . In total, $103(4 \times 25$ aerosol +2 gas +1 meteorological $)$ tracers are advected. For plotting purposes, an ice crystal size grid is defined with 50 bins and a bin volume ratio of 1.75 . The $\mathrm{H}_{2} \mathrm{O} / \mathrm{H}_{2} \mathrm{SO}_{4} / \mathrm{HNO}_{3}$ particles have a total number density of $200 \mathrm{~cm}^{-3}$, a mean number radius of $0.02 \mu \mathrm{m}$, and a width of 2.3. The results are not sensitive to the specific choice of these aerosol parameters.

The most important feature seen in $S_{i}(z)$ in Fig. 1 is the tongue of moist, supersaturated air centered at $8.5 \mathrm{~km}$. As shown below, the first cloud particles begin to form right above this altitude.

\subsection{Ice supersaturation and microphysical properties}

The evolution of the column-integrated ice crystal number densities, ice water path, and optical depth (not shown here), as well as the temporal development of the vertical distribution of ice water content and ice crystal number density of the Arctic cirrostratus calculated with the APSCm-1-D agree well with those presented by Lin et al. (2005). It is encouraging that the two models generally lead to similar results for homogeneous freezing in Arctic cirrostratus concerning basic cloud microphysical properties, although they are conceptually different (size-segregated representation of ice crystals versus particle-in-cell code) and rely on thermodynamic functions derived from different sources (freezing rate coefficients and aerosol vapor pressures). Slightly more crystals form in the present simulation which may be caused by small differences in the homogeneous freezing rates.

Figure 2 shows the ice saturation ratio (left panel, top) and the ice crystal number density $n_{i}$ (right panel, top) as a function of height and time. The steady uplift increases $S_{i}$ which attains its maximum value 1.52 at $216 \mathrm{~K}$ after about $1 \mathrm{~h}$ at $8.75 \mathrm{~km}$. The fact that $S_{i}$ then declines rapidly at this level indicates that ice crystals have formed. The region in which homogeneous freezing is active lies within the $S_{i}=1.4$ contour line.

Crystal concentrations reach values up to $0.4 \mathrm{~cm}^{-3}$ within $20 \mathrm{~min}$ in the early formation zone. High $S_{i}$ values are transported upwards and define a rather thin cloud top layer, which is characterized by continuous formation of ice crystals throughout the simulation. In the rising top layer, $n_{i}$ increases with altitude up to $0.12 \mathrm{~cm}^{-3}$ because of declining temperatures.

Below the initial formation layer, homogeneous freezing also occurs but only up to $\sim 140 \mathrm{~min}$. The termination of freezing there is caused by sedimenting ice crystals that quickly deplete the gaseous $\mathrm{H}_{2} \mathrm{O}$ reservoir in the highly supersaturated layers through which they fall. Above these layers, a region exists where a fall streak is visible in terms of $n_{i}$ and where $S_{i}$ stays close to, but above, saturation (see 

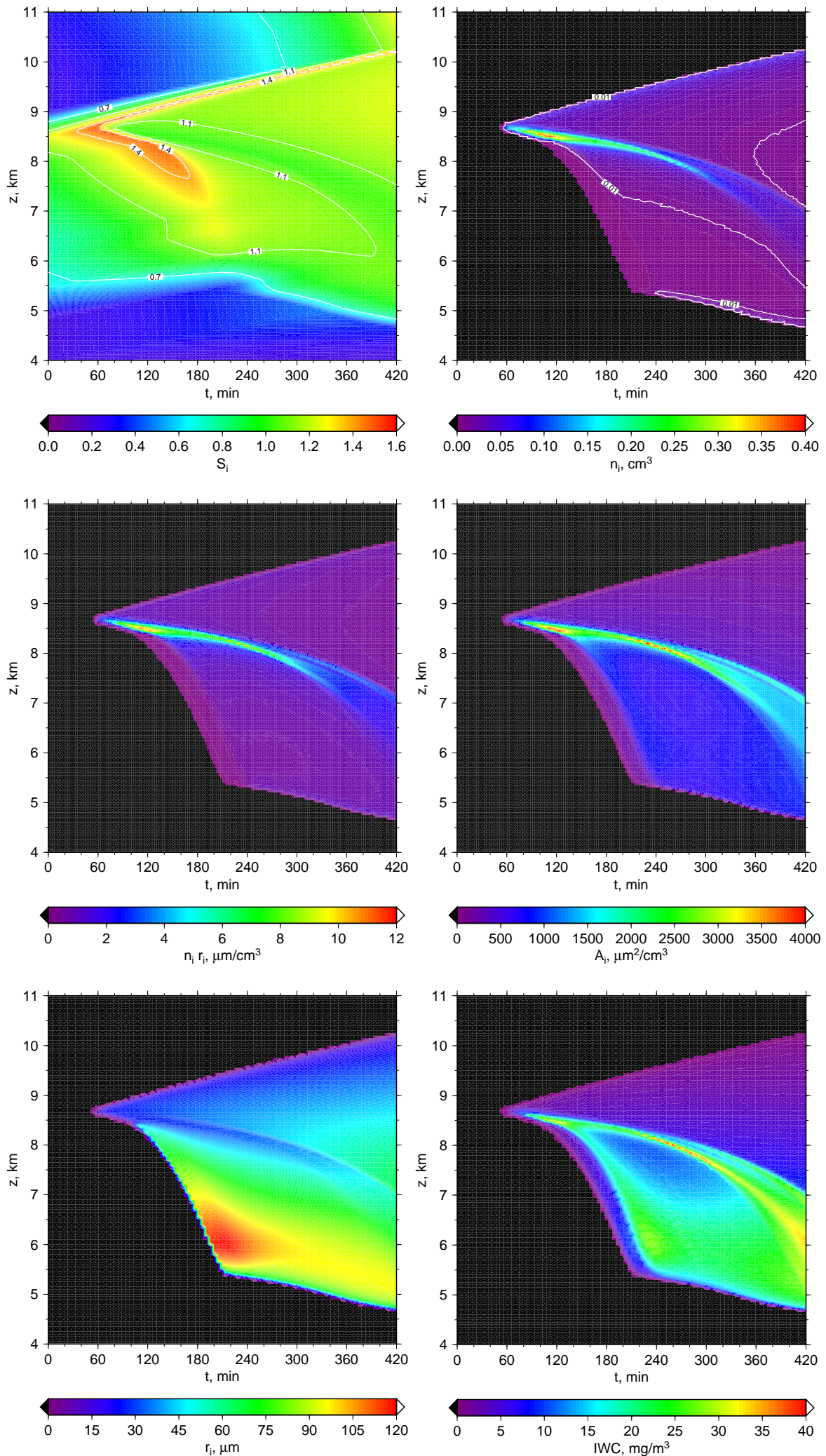

Fig. 2. Temporal evolution of the ice saturation ratio and the moments of the ice crystal size distributions as a function of altitude. Ice saturation ratio $S_{i}$ (top left), ice crystal number density $n_{i}$ (top right), size-weighted ice crystal number density $n_{i} r_{i}$ (mid left), specific surface area density $A_{i}$ (mid right), mean ice crystal effective spherical radius $r_{i}$ (bottom left), and ice water content IWC (bottom right). 


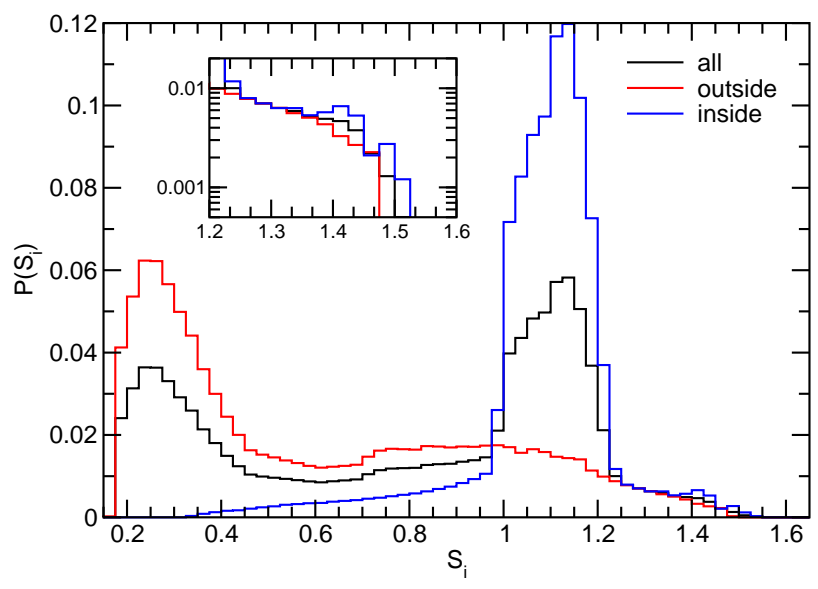

Fig. 3. Probability distributions of ice saturation $S_{i}$ taken inside and outside the cloud as well as the total probability averaged over the entire computational domain $(0-7 \mathrm{~h}, 4-11 \mathrm{~km}$. The distributions are normalized to the respective total number of data points in each case. The inset enlarges the highly supersaturated tail of the distributions.

the $S_{i}=1.1$ contour line). Between the top layer and the fall streak, saturation ratios as high as 1.25 build up $(8.5-10 \mathrm{~km}$ at $7 \mathrm{~h}$ ), because the crystals forming above are too small to fall into this layer and the early-forming crystals have already fallen out of it.

The $n_{i}=0.01 \mathrm{~cm}^{-3}$ contour line indicates that low concentrations prevail in the regions away from the top layer and the fall streak. At the cloud base, $n_{i}$ exhibits a sharp increase, because crystals fall in already subsaturated air (see the $S_{i}=0.7$ contour line) and evaporate. The resulting reduction of their terminal fall speed causes the formation of this thin, concentrated layer.

Figure 2 also shows the evolution of the product $n_{i} r_{i}$ determining the relaxation times of the in-cloud ice supersaturation as discussed below (left panel, middle) and the specific cloud surface area density $A_{i}$ (right panel, middle). Typical values for $A_{i}$ within the fall streak reach up to $4000 \mu \mathrm{m}^{2} \mathrm{~cm}^{-3}$, while the region below the fall streak is characterized by values in the range $500-1000 \mu \mathrm{m}^{2} \mathrm{~cm}^{-3}$. Values of $A_{i}$ in the cloud top region near the tropopause never exceed a few $100 \mu \mathrm{m}^{2} \mathrm{~cm}^{-3}$.

Contrary to the conjecture of Reichardt et al. (2002), supersaturation with respect to ice occurs at times in this type of cloud. This is best illustrated with the help of Fig. 3 showing the probability distributions of $S_{i}$ in the total computational domain $(4-11 \mathrm{~km}, 0-7 \mathrm{~h})$ as a black histogram, together with the distributions taken inside (blue histogram) and outside (red histogram) of the cloud.

The out-of-cloud distribution reflects the initial $S_{i}$-profile and the action of adiabatic cooling consistent with the regions void of ice in Fig. 2, with a maximum between $S_{i}=0.2-0.4$. The in-cloud distribution peaks in the super-

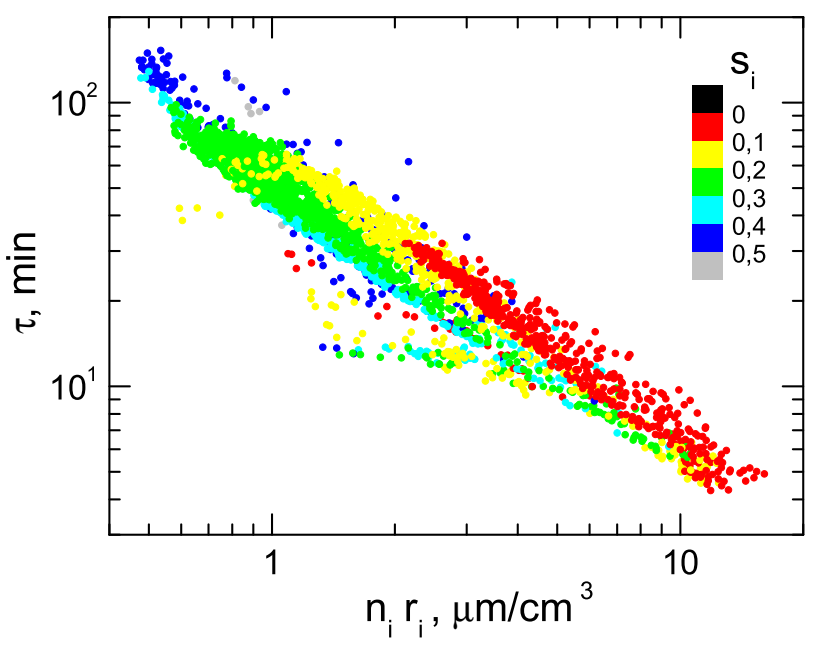

Fig. 4. Scatter plot of ice supersaturation relaxation times $\tau$ as a function of $n_{i} r_{i}$. The symbols are color-coded by the respective supersaturations $s_{i}=S_{i}-1$. The data points are representative for the relaxation phase in and below the fall streak region of the cloud.

saturated region, between $S_{i}=1-1.2$, indicating that most of the ice crystals experience growth conditions.

It is very interesting to note that some crystals survive in strongly subsaturated air, down to $S_{i}=0.35$, as seen by the left tail of the in-cloud distribution. This can happen because large ice crystals need quite a long time to fully evaporate at low temperatures while falling through subsaturated layers. The existence of ice in rather dry air has been demonstrated in in-situ observations of midlatitude cirrus (Ström et al., 2003).

Finally, the total distribution is a blend of the in-cloud and out-of-cloud parts, and contains both the dry and moist maxima. The distributions exhibit several salient features, such as the dry and moist maxima and the quasi-exponential tails in supersaturated air (Kärcher and Haag, 2004), but their detailed shapes depend on the sampling process. The high $S_{i}$ tails are shown enlarged in the inset in Fig. 3. The peak $S_{i}$ inside cloud is about 0.05 higher than the maximum $S_{i}$ outside cloud because of ongoing cooling during nucleation. Such differences are also seen in freezing chamber measurements (Haag et al., 2003a) and in distributions of $S_{i}$ taken in the field within and nearby cirrus clouds (Haag et al., 2003b).

The main reasons responsible for the high in-cloud relative humidities are (i) the continuous (albeit relatively slow) cooling which produces supersaturation in regions where the ice crystal concentrations are low and (ii) the low temperatures which lead to rather slow removal rates of gaseous $\mathrm{H}_{2} \mathrm{O}$ on growing ice particles.

A scatter plot of $e$-folding times $\tau$ for the relaxation of the ice supersaturation $s_{i}=S_{i}-1$ shown in Fig. 4 supports the above discussion of high in-cloud relative humidities. The relaxation times are extracted from the model every $6 \mathrm{~min}$ at 


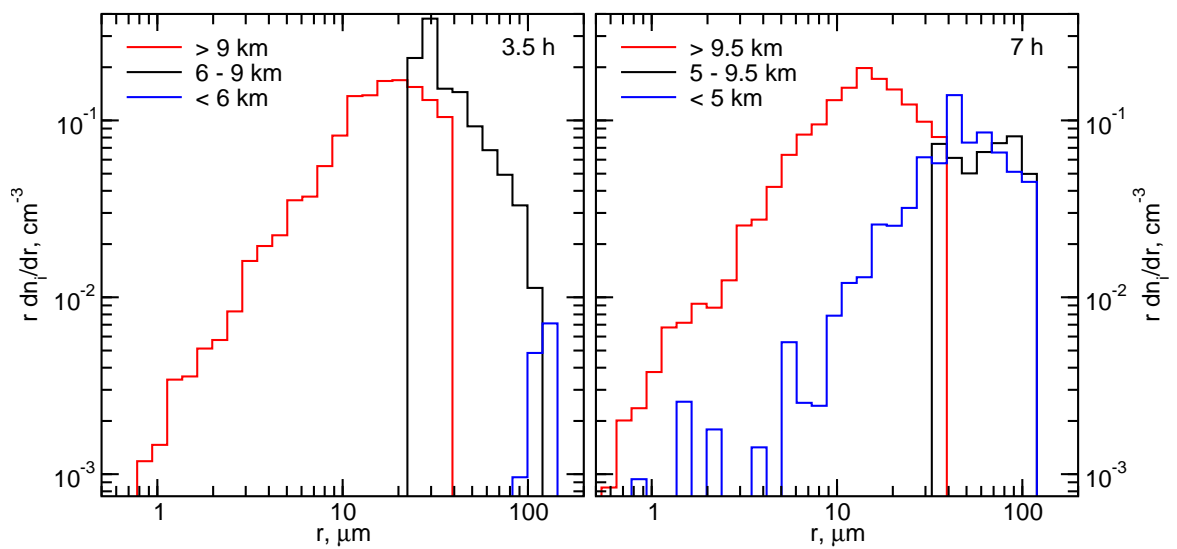

Fig. 5. Average ice crystal size distributions after 3.5 (left) amd $7 \mathrm{~h}$ (right) extracted from the cloud top or formation regions (red), the cloud base or evaporation regions (blue), and the cloud interior (black). At $3.5 \mathrm{~h}(7 \mathrm{~h})$, the lower and upper cloud boundaries are located at 5.51 (4.69) km and $9.41(10.23) \mathrm{km}$.

each vertical level within and below the fall streak (as visible in $n_{i}(z, t)$ in Fig. 2) whenever $s_{i}>0$ according to

$\tau=\left(\frac{1}{s_{i}}\left|\frac{d s_{i}}{d t}\right|\right)^{-1}$.

This definition of $\tau$ includes both a deposition term (reducing $s_{i}$ in proportion to $n_{i} r_{i}$ in the diffusional growth limit) and a cooling term (increasing $s_{i}$ in proportion to the updraft speed $w)$. It describes relaxation toward a steady-state in which cooling is balanced by deposition (see Appendix for more details). For a developed, non-evaporating cloud the cooling term is negligible, so that $\tau \propto 1 /\left(n_{i} r_{i}\right)$, describing relaxation toward the equilibrium ice saturation.

In Fig. 4, points with $\left|d s_{i} / d t\right|<5 \times 10^{-5}$ are excluded to eliminate cases with excessively high $\tau$. The $\tau$-values are color-coded by $s_{i}$. The results show that $\tau$ generally decreases inversely proportional to $n_{i} r_{i}$ in the relaxation phase, as expected, and ranges between 4-150 min. These rather long timescales are mainly caused by the low temperatures, and render the high in-cloud supersaturations $(0.1-0.3)$ as discussed above plausible (red, yellow, and green symbols). The highest supersaturations $(0.4-0.5)$ only occur prior to homogeneous freezing (dark blue and gray symbols) and are comparatively rare events. As a general trend, $\tau$-values with high $s_{i}$ (gray and bluish colors) associated with fresh nucleation events appear over the entire range of $n_{i} r_{i}$, depending on nucleation conditions. For aging clouds increases in $n_{i} r_{i}$ are correlated with decreases in $s_{i}$ (red, yellow, and green colors), indicative of depositional growth.

These findings are in general agreement with results presented by Jensen et al. (2005a) for the case of a subtropical tropopause cirrus layer developing in similar ambient conditions, but driven by mesoscale temperature fluctuations. In particular, high ice supersaturations are only found in homogeneous freezing regions or when ice crystals sediment into supersaturated air.

\subsection{Ice crystal size distributions and dehydration}

Also shown in Fig. 2 are the mean values of the effective spherical radius $r_{i}$ of ice crystals (left panel, bottom) and the cloud ice water content IWC (right panel, bottom). At the cloud top, where homogeneous freezing is active, crystal radii are small $(10-30 \mu \mathrm{m})$. They are also small in the slightly supersaturated fall streak initially, but grow to sizes of $\sim 80 \mu \mathrm{m}$ towards the end of the simulation. The biggest crystals $(120 \mu \mathrm{m})$ appear after $3 \mathrm{~h}$ at rather low altitudes ( $\sim 6 \mathrm{~km})$; these few crystals were produced earliest and could fall sufficiently long through the highly supersaturated layer below the initial formation zone. They slowly evaporate while sedimenting further down.

The cloud base is characterized by the sharp decrease of $r_{i}$, as is the cloud top. At intermediate altitudes, away from the fall streak, the cloud is very tenuous, with $n_{i}$ values of $0.01 \mathrm{~cm}^{-3}$ or less and $r_{i}$ in the range $20-60 \mu \mathrm{m}$. Correspondingly, the IWC distribution shows a maximum along the fall streak and around the $6 \mathrm{~km}$ level after $3 \mathrm{~h}$.

A precise knowledge of the vertical distribution of ice crystals as a function of their size is required for the use of radiative cirrus models and the improvement of satellite retrieval algorithms. The crystal size distributions at different times and locations are quite variable. It is therefore instructive to inspect these size distributions after 3.5 and $7 \mathrm{~h}$ averaged over the cloud top region, the cloud base region, and in the cloud interior with the help of Fig. 5.

After $3.5 \mathrm{~h}$ (left panel), at the cloud top, mean crystal radii peak near $10 \mu \mathrm{m}$ and crystals larger than $40 \mu \mathrm{m}$ are absent. The distribution extends down to the sizes of the freezing aerosol particles $(0.5-1 \mu \mathrm{m})$, indicative of ongoing freezing. Interestingly, this feature is seen in young midlatitude (Schröder et al., 2000) and thin tropical cirrus (Thomas et al., 2002) ice crystal size distributions. However, difficulties in 

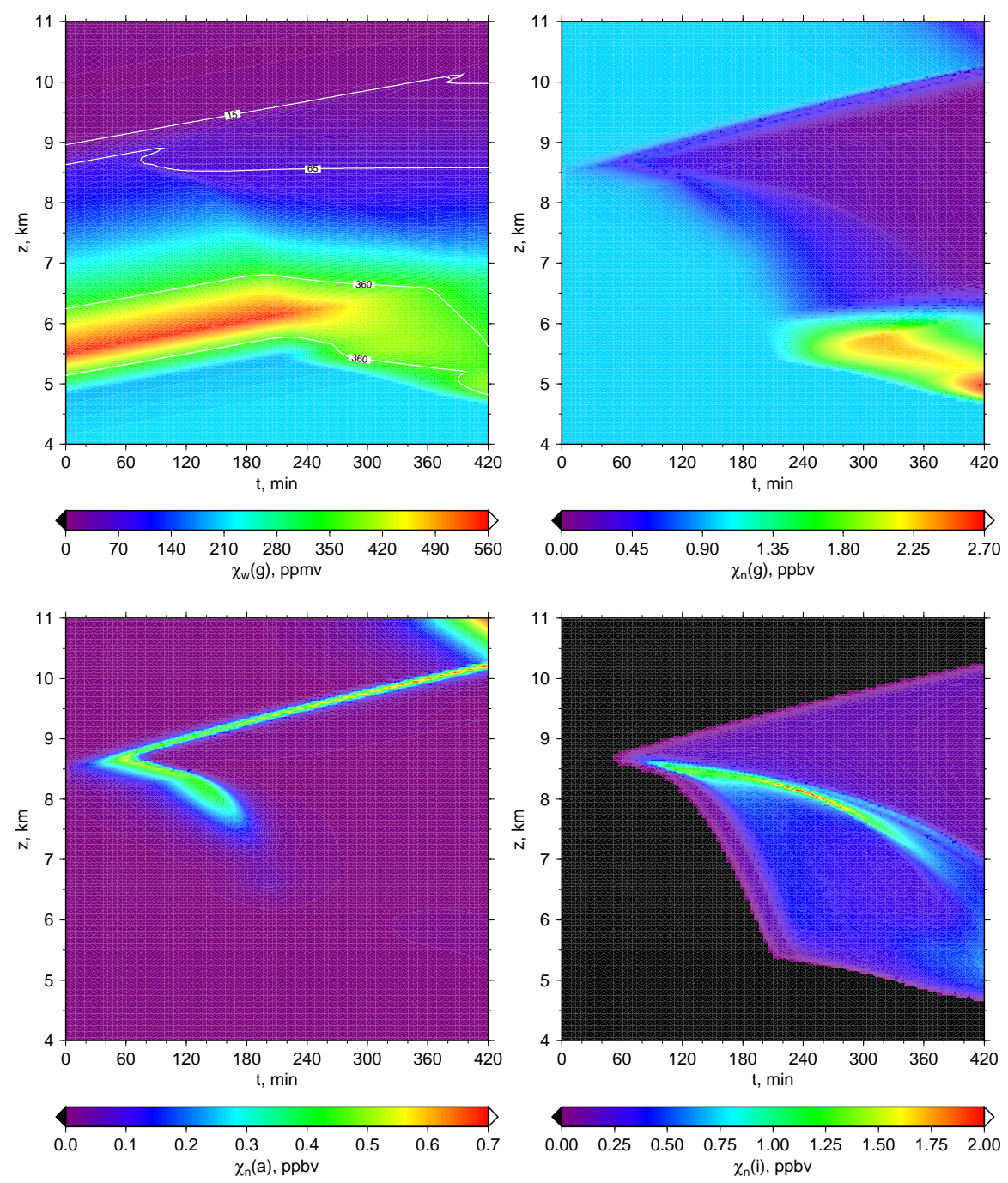

Fig. 6. $\mathrm{H}_{2} \mathrm{O}$ gas mixing ratio $\chi_{w}$ (top left), $\mathrm{HNO}_{3}$ gas mixing ratio $\chi_{n}$ (top right), $\mathrm{HNO}_{3}$ aerosol mixing ratio (bottom left), and $\mathrm{HNO} \mathrm{O}_{3}$ ice mixing ratio (bottom right) as a function of altitude and time. The baseline value $Q=10.5 \mathrm{kcal} \mathrm{mol}^{-1}$ is assumed to describe $\mathrm{HNO}_{3}$-ice interaction. The amount of $\mathrm{HNO}_{3}$ residing in the liquid particles prior to freezing is retained in the ice phase.

analysing data from optical particle probes for ice crystals with sizes below $10 \mu \mathrm{m}$ do not allow a closer comparison to be made. The small particles sediment only slowly with terminal fall speeds below $360 \mathrm{~m} / \mathrm{h}$, or below $180 \mathrm{~m} / \mathrm{h}$ relative to the uplift. The cloud base region has received the few large crystals that formed first (see above). In the cloud region between top and base, the size spectrum extends from $20-100 \mu \mathrm{m}$; the peak at $30 \mu \mathrm{m}$ belongs to the numerous crystals within the fall streak.

While the situation at the cloud top after $7 \mathrm{~h}$ (right panel) has not changed significantly because homogeneous freezing is continuously active, small ice crystals are now absent throughout most of the cloud interior and the radii range between 30 and $100 \mu \mathrm{m}$. It is possible that the real Arctic cloud contained even larger crystals formed by aggregation, a pro- cess not included in this model. In contrast to the earlier cloud stage, the cloud base region now also contains a few $\mu \mathrm{m}$-sized crystals produced by evaporation. The size spectrum there is noisy at the low size end because evaporation is rapid.

Figure 6 gives an overview of the evolution of $\mathrm{H}_{2} \mathrm{O}$ and $\mathrm{HNO}_{3}$ gas mixing ratios (top panel) and the $\mathrm{HNO}_{3}$ content in STS and cirrus particles (bottom panel) expressed in equivalent air volume mixing ratios. The initial $\mathrm{H}_{2} \mathrm{O}$ profile shown in Fig. 1 appears to be purely advected prior to cirrus formation, indicating that the aerosol water content is neglible compared to total water. As soon as ice forms, gas phase $\mathrm{H}_{2} \mathrm{O}$ is quickly transferred to the ice phase, as indicated by the contour lines $\chi_{w}=15 \mathrm{ppmv}$ and $65 \mathrm{ppmv}$. After $3 \mathrm{~h}$, the $6.5 \mathrm{~km}$ level also becomes affected, but the air 


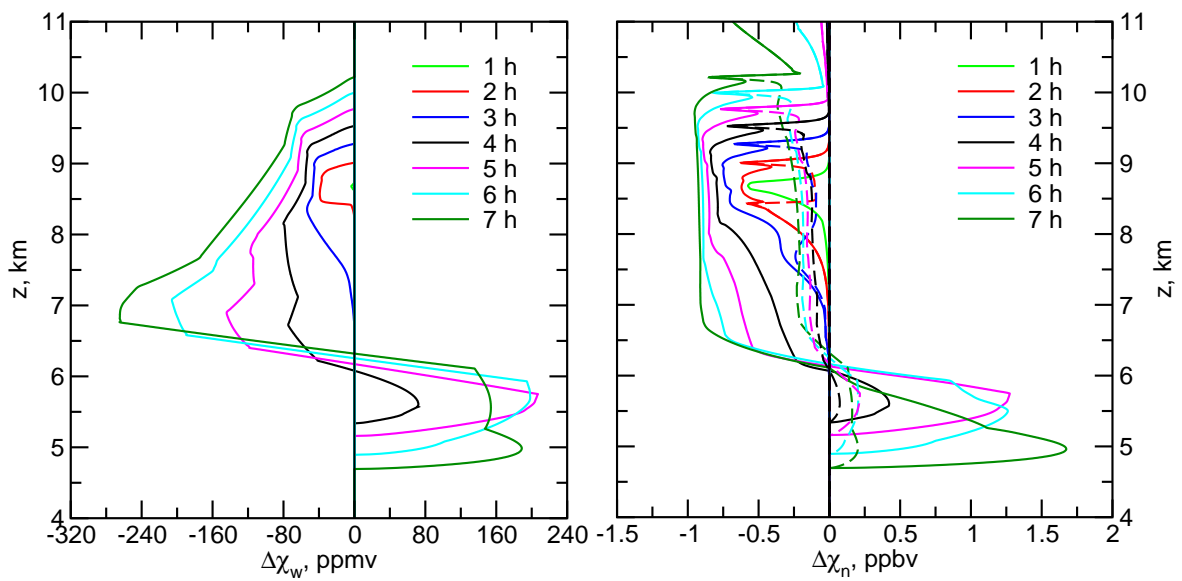

Fig. 7. Vertical profiles showing the combined result of sequestration of $\mathrm{H}_{2} \mathrm{O}$ (left) and $\mathrm{HNO}_{3}$ (right) in STS particles and ice crystals and the subsequent sedimentation (in the case of ice) and evaporation of these particles at selected cloud ages. The initial profile of total $\mathrm{HNO}_{3}$ is constant, $\chi_{n}(z)=1 \mathrm{ppbv}$, and gaseous $\chi_{w}(z)$ decreases with altitude as shown in Fig. 1 . Shown are the differences $\Delta \chi$ between the actual profiles of gas phase $\mathrm{H}_{2} \mathrm{O}$ and $\mathrm{HNO}_{3}$ and the respective initial profiles advected as passive tracers. The excursions to positive $\Delta \chi$-values at the lower altitudes show that rehydration and renitrification occurred. The respective evolutions of condensed-phase $\mathrm{H}_{2} \mathrm{O}$ and $\mathrm{HNO}_{3}$ are shown in Figs. 2 and 5, respectively. Solid curves correspond to Fig. 5 (baseline value $Q=10.5 \mathrm{kcal} \mathrm{mol}^{-1}$ ) and dashed curves assume $Q=9 \mathrm{kcal} \mathrm{mol}^{-1}$ mimicking less efficient uptake of $\mathrm{HNO}_{3}$ on ice.

there is moistened again toward the end of the simulation $\left(\chi_{w}=360\right.$ ppmv contour line).

To further examine the vertical redistribution of $\mathrm{H}_{2} \mathrm{O}$ and $\mathrm{HNO}_{3}$, the initial mixing ratios $\chi_{w}(z)$ and $\chi_{n}(z)$ are advected as passive tracers (no interaction with particles), yielding $\chi_{w}^{t}(z, t)$ and $\chi_{n}^{t}(z, t)$. The difference $\Delta \chi_{w}=\chi_{w}-\chi_{w}^{t}$ then describes the affect of ice uptake and sedimentation on $\mathrm{H}_{2} \mathrm{O}$ and is shown in Fig. 7 at selected cloud ages. This approach describes the potential for dehydration and denitrification to occur.

The $\mathrm{H}_{2} \mathrm{O}$ profiles (left panel) show clear signs of cloud formation, starting in the nucleation region around $8.5 \mathrm{~km}$ after $1 \mathrm{~h}$. In the course of time, ice water is produced within an increasing vertical column, until after $4 \mathrm{~h}, \mathrm{H}_{2} \mathrm{O}$ molecules evaporate back to the gas phase in the cloud base region. Recalling the absolute $\mathrm{H}_{2} \mathrm{O}$ mixing ratios from Fig. 6, this Arctic cloud causes a substantial drying of upper tropospheric air, supporting the tentative interpretation of the cause of low water contents observed in the Arctic upper troposphere and lower stratosphere region (Murphy et al., 1990; Kelly et al., 1991; Schiller et al., 1999; Pfister et al., 2003).

The present work shows that mesocale temperature fluctuations driven by buoyancy waves unresolved in the present study are not necessarily required to explain persistent incloud supersaturation, but may cause more frequent activation of homogeneous freezing by broadening the distributions of relative humidity in the supersaturated regions (Kärcher and Haag, 2004). This is consistent with other model studies suggesting that cirrus formation mostly takes place in synoptic cold pools, but with microphysical properties controlled by mesoscale dynamical variability prevail- ing in these synoptic-scale ice supersaturated regions (Jensen and Pfister, 2004; Haag and Kärcher, 2004).

The addition of small-scale fluctuations will lead to more but smaller ice crystals. Dynamical variability at the scale of the cloud may at least in part be responsible for the multiple fall streaks visible in the observed Arctic cirrostratus (Reichardt et al., 2002), but are missing in the present simulation. It is not fully clear whether the inclusion of unresolved dynamical variability reduces the potential of the cloud to vertically transport $\mathrm{H}_{2} \mathrm{O}$ (and $\mathrm{HNO}_{3}$, see next section) due to lower ice crystal sedimentation speeds. An increased number of nucleation events and multiple falls streaks could overcompensate this effect. To include realistic forcing patterns (e.g., variations in vertical winds and temperatures on horizontal scales at or below $\sim 1-10 \mathrm{~km}$ ) is beyond the scope of this study but will be examined in future work.

\subsection{Nitric acid uptake and denitrification}

A comparison of $\chi_{n}(g)$ and $\chi_{n}(a)$ in Fig. 6 reveals that little $\mathrm{HNO}_{3}$ partitions in STS particles when $T$ stays below the frost point near the cold tropopause (Kärcher and Solomon, 1999). Uptake in STS particles becomes relevant when $S_{i}>1.2-1.3$, which can be seen by comparing the shape of enhanced $\chi_{n}(a)$-values with the $S_{i}=1.4$ contour line in Fig. 2. When ice particles form, more $\mathrm{HNO}_{3}$ molecules partition in ice crystals, in particular within the fall streak region as indicated by $\chi_{n}(i)$. In the course of time, the region into which ice crystals sediment from the cloud top is characterized by very low $\mathrm{HNO}_{3}$ gas phase mixing ratios, while $\mathrm{HNO}_{3}$ is released back to the gas phase in the cloud base region where evaporation of ice prevails. 


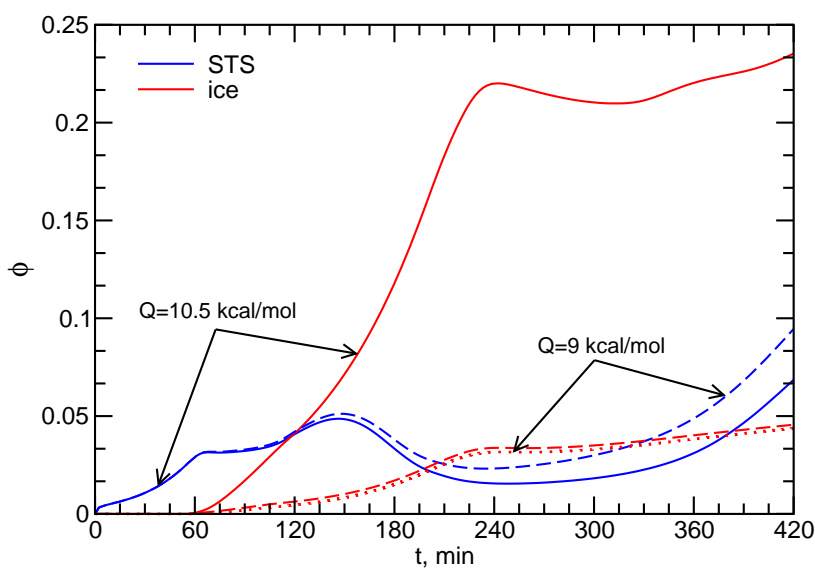

Fig. 8. Column-integrated phase partitioning fractions $\phi$ of $\mathrm{HNO}_{3}$ in the liquid ternary aerosol (blue curves) and ice (red curves) particles for the baseline case (solid curves) and the case with less efficient $\mathrm{HNO}_{3}$ uptake on ice (dashed curves) for which also a model run assuming no retention of $\mathrm{HNO}_{3}$ is shown (dotted curve).

In Fig. 7 (right panel), the difference $\Delta \chi_{n}=\chi_{n}-\chi_{n}^{t}$ describes the affect of dissolution in STS particles and ice uptake and sedimentation on $\mathrm{HNO}_{3}$. The $\mathrm{HNO}_{3}$ profiles in the baseline case (solid curves) likewise show clear signs of uptake in cirrus particles and resulting denitrification, and renitrification in the cloud base region. The cloud amount suffices to practically partition all available $\mathrm{HNO}_{3}(1 \mathrm{ppbv})$ in the ice phase. The amount of $\mathrm{HNO}_{3}$ taken up over a region extending from $6-9 \mathrm{~km}$ within $4 \mathrm{~h}$ is evaporated within an only $1.5 \mathrm{~km}$ thick region at mid-tropospheric levels, increasing the mixing ratios there by more than $150 \%$.

A difference to the water uptake is that a significant amount of $\mathrm{HNO}_{3}$ is also taken up by the STS particles prior to freezing (before $1 \mathrm{~h}$ ) and throughout the simulations in regions where $T$ is low and $S_{i}$ is high and void of crystals (above the cloud top and near the cloud edges), consistent with Fig. 6. As soon as ice forms, $S_{i}$ (and thus the $\mathrm{HNO}_{3}$ vapor pressure) is reduced, driving $\mathrm{HNO}_{3}$ out of the liquid solution droplets back into the gas phase, where it is available for uptake on the growing ice crystals. The sharp peak in the $\Delta \chi_{n}$-curves in Fig. 7 marks this transition region, and is carried upwards by the continuous uplift where it becomes more pronounced because of the lower $T$ higher up.

In the trapping model used to predict the $\mathrm{HNO}_{3}$ interaction with growing ice crystals (recall Sect. 2.4), the $Q$-values which mainly determine the time of adsorption $1 / k$ are not well known. The partitioning of $\mathrm{HNO}_{3}$ in cirrus can be sensitive to variations of $Q$, so it is illustrative to study results obtained with a different choice of this parameter.

Figure 7 shows almost complete removal of $\mathrm{HNO}_{3}$ from the gas phase in the mature cloud. The case with $Q=9 \mathrm{kcal} \mathrm{mol}^{-1}$, that is, with shorter times of adsorption, is also shown (dashed curves). The effects on the $\mathrm{HNO}_{3}$ pro- files are quite dramatic; throughout most of the cloud column, gas phase mixing ratios are now reduced by no more than 0.25 ppbv. Consequently, denitrification is much less pronounced, reaching similarly weak enhancements below $6 \mathrm{~km}$ altitude after $4 \mathrm{~h}$.

The main reason for this strong sensitivity on the vertical distribution of $\mathrm{HNO}_{3}$ is that uptake is neither fully controlled by gas diffusion nor by surface processes for $Q$-values in the region 8-12 kcal mol${ }^{-1}$ (Kärcher and Basko, 2004). Under the conditions relevant to this study, the trapping efficiency switches between the two limiting cases of pure diffusional trapping and trapping of equilibrium surface concentrations represented by Eqs. (5) and (6), respectively.

The following estimates serve to illustrate this point. The number of $\mathrm{HNO}_{3}$ molecules that would escape from a static surface at $T=210 \mathrm{~K}$ is given by $k \simeq 35(1290) \mathrm{s}^{-1}$ for $Q=10.5$ (9) $\mathrm{kcal} \mathrm{mol}^{-1}$. The more ice layers that are added in a given time interval, the less likely it becomes for adsorbed molecules to escape from the surface. The number of ice monolayers added per second is given by $\dot{r}_{i} /\left(v_{w} \sigma_{w}\right) \simeq 7 \mathrm{~s}^{-1}$ with the specific volume of $\mathrm{H}_{2} \mathrm{O}$ molecules in ice $v_{w}=3 \times 10^{-23} \mathrm{~cm}^{3}$, the maximum number of surface sites for water deposition $\sigma_{w}=10^{15} \mathrm{~cm}^{-2}$, and the standard diffusional growth rate $\dot{r_{i}} \simeq 0.13 \mu \mathrm{m} \mathrm{min}^{-1}$ evaluated at $210 \mathrm{~K}, p=220 \mathrm{hPa}, r_{i}=10 \mu \mathrm{m}$, and $s_{i}=0.05$. This shows that trapping is much less effective for $Q=9 \mathrm{kcal} \mathrm{mol}^{-1}$ as the time of adsorption decreases by a factor of $35 / 1290 \simeq 0.03$ compared to the baseline case.

Figure 8 depicts the phase partitioning fractions $\phi$ of $\mathrm{HNO}_{3}$ into STS particles and ice crystals integrated over the entire vertical column $(4-11 \mathrm{~km})$ as as function of time. For both $Q$-values, similar amounts of $\mathrm{HNO}_{3}$ dissolve in the liquid particles initially, but somewhat more $\mathrm{HNO}_{3}$ partitions in the aerosol phase when $Q$ is lowered and uptake into ice is reduced (dashed curves). Toward the end of the simulation, $\phi$ in aerosols starts to increase quite rapidly. This is caused by the very low temperatures above the cloud top $(<205 \mathrm{~K})$, favoring nearly complete dissolution of $\mathrm{HNO}_{3}$ in the STS particles in the absence of cloud ice (see also Fig. 6). In the tropopause region, significantly more $\mathrm{HNO}_{3}$ can dissolve when ammonium is additionally present in the background aerosol particles, depending on the degree of ammoniation (Kärcher and Solomon, 1999). In any case, the amount of $\mathrm{HNO}_{3}$ contained in them would be released back to the gas phase roughly at the same altitudes as soon as $T$ rises above the $\mathrm{HNO}_{3}$ dew point temperature.

While for the baseline case trapping in ice becomes more important than dissolution in STS particles after $120 \mathrm{~min}$ and reaches an average level of $\sim 20 \%$, this happens only after $210 \mathrm{~min}$ in the case with reduced ice uptake, where less than $5 \%$ of the $\mathrm{HNO}_{3}$ molecules are associated with the ice phase.

The dotted curve for $\phi$ in ice has been obtained by setting the $\mathrm{HNO}_{3}$ retention coefficient equal to zero in the $Q=9 \mathrm{kcal} \mathrm{mol}^{-1}$ case, that is, by assuming that the total amount of $\mathrm{HNO}_{3}$ present in the freezing STS particles is 
released to the gas phase and is not fully retained in the newly formed ice crystals. (Recall that the other curves assume full retention.) Here, $\phi$ in ice is slightly reduced and correspondingly more $\mathrm{HNO}_{3}$ partitions in the gas phase. In contrast, a zero retention coefficient has no effect on the $Q=10.5 \mathrm{kcal} \mathrm{mol}^{-1}$ result (not shown in Fig. 8). This is because the $\mathrm{HNO}_{3}$ molecules released to the gas phase upon freezing are quickly trapped in the growing, newly formed ice crystals, while this trapping is less efficient in the $Q=9 \mathrm{kcal} \mathrm{mol}^{-1}$ case. Hence it may be concluded that uncertainties in retention factors only affect species that do not adsorb efficiently on ice surfaces in cold cirrus.

Before addressing pending uncertainties, the predictions of the trapping concept are compared to the more conventional approach of calculating the amount of $\mathrm{HNO}_{3}$ associated with cirrus ice particles by assuming a local equilibrium between adsorption and desorption at the surfaces of ice particles, but not allowing the amount absorbed to be trapped during ice growth as if the ice crystals stayed at saturation. This approach mimicks the way most field measurements of $\mathrm{HNO}_{3}$ uptake have been analyzed in the past (e.g., Kondo et al., 2003; Ziereis et al., 2004; Popp et al., 2004).

Dissolution of $\mathrm{HNO}_{3}$ into STS particles is treated as before. The remaining partial pressure $p_{n}, T$, and the ice surface area density $A_{i}$ then determine the amount per $\mathrm{cm}^{3}$ of air that would be adsorbed in equilibrium at a static surface according to $A_{i} \sigma_{n} \Theta\left(T, p_{n}\right)$, where the choice $\sigma_{n}=10^{15} \mathrm{~cm}^{-2}$ maximizes the number of available surface sites for adsorption of $\mathrm{HNO}_{3}$ and $\Theta$ is the fractional surface coverage calculated from the equilibrium isotherm (see above). Here, as in many previous analyses, a saturated, dissociative Langmuir isotherm determines the functional form of $\Theta$, with the same parameters as given by Popp et al. (2004), except for $Q$, which is set equal to $10.5 \mathrm{kcal} \mathrm{mol}^{-1}$ as in the trapping case.

Figure 9 repeats the solid curves from Fig. 8 for the baseline case, but includes results from the conventional approach as dashed curves. In the latter case, the amount $\phi$ of $\mathrm{HNO}_{3}$ associated with cirrus particles reaches only $0.4 \%$ after $7 \mathrm{~h}$, compared to $20 \%$ in the trapping scenario. The increased amount of $\mathrm{HNO}_{3}$ in the gas phase leads to an increase of $\mathrm{HNO}_{3}$ dissolved in STS particles. These results demonstrate that without trapping, the amount of cirrus-bound $\mathrm{HNO}_{3}$ will be underestimated.

However, the current state of knowledge does not allow robust conclusions to be drawn. Dissociative Langmuir isotherms may not be appropriate to describe $\mathrm{HNO}_{3}$ adsorption, although they seem to fit $\Theta$-data inferred from cirrusbound $\mathrm{HNO}_{3}$ measured in the field reasonably well. Recent laboratory equilibrium studies have revealed that for typical upper tropospheric $\mathrm{HNO}_{3}$ partial pressures $\left(<10^{-7} \mathrm{hPa}\right)$, the amount of adsorbed $\mathrm{HNO}_{3}$ is better described by a nondissociative Langmuir isotherm (Ullerstam et al., 2005).

The trapping model as employed here is based on an unsaturated, non-dissociative Langmuir isotherm (recall

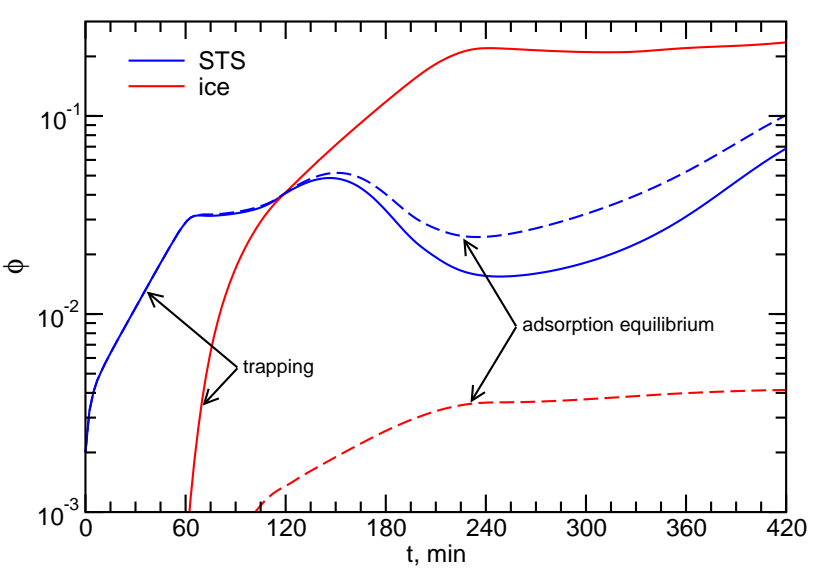

Fig. 9. As Fig. 8, again with the solid curves representing the baseline case but now on a logarithmic scale. The dashed curves have been obtained by assuming instantaneous adsorption equilibrium of $\mathrm{HNO}_{3}$ on ice according to a saturated dissociative Langmuir isotherm, as frequently done in the interpretation of updake data.

Sect. 2.4), but the initial $\mathrm{HNO}_{3}$ mixing ratio of $1 \mathrm{ppb}$, corresponding to $(2-3) \times 10^{-7} \mathrm{hPa}$, is high enough for saturation effects to become important. It is thus necessary to generalize the trapping model to include saturated adsorption in order to properly cover the high pressure regime.

If trapping of $\mathrm{HNO}_{3}$ takes place near the adsorptionlimited regime governed by Eq. (5), it is possible that information about the form of the adsorption isotherm is "conserved" during trapping. This could potentially explain why $\Theta$-values inferred from measured $\mathrm{HNO}_{3}$ contents in ice particles resemble adsorption isotherms. Much of the scatter seen in inferred $\Theta$ may then be caused by trapped $\mathrm{HNO}_{3}$. However, a sound comparison with field measurements is only possible after the yet poorly constrained model parameters have been fixed.

\section{Conclusions}

Using a relatively well documented case study of a longlived, geometrically and optically thick Arctic cirrostratus cloud as a basis, the processes controlling supersaturation, cloud microphysical properties, and the potential for dehydration and denitrification of upper tropospheric air have been examined with the help of a one-dimensional cirrus cloud model with explicit aerosol and ice microphysics. The specific results are summarized as follows.

1. Continuous weak cooling of air in regions with small amounts of ice and slow ice deposition rates of water vapor at low temperatures drive significant in-cloud supersaturations over ice.

2. Ice crystal size distributions are characterized by high number concentrations of small crystals in the cloud top 
region near the tropopause, broad but highly variable size spectra in the cloud interior, and mostly large crystals in the cloud base region. At and below the cloud base, broadening of the size distribution occurs due to evaporating ice crystals.

3. Large ice crystals may survive falling through even strongly subsaturated cloud layers, because they need a long time to fully evaporate at low temperatures.

4. Weakly forced, vertically extended polar cirrus clouds are highly efficient at dehydrating the upper troposphere. They could also denitrify upper tropospheric air masses efficiently.

5. Low temperatures, high supersaturation ratios over ice, and the absence of ice above but close to the cloud top region causes efficient uptake of nitric acid in background supercooled ternary solution particles.

The above results stimulate further research in this area and should be considered in the future.

The findings that Arctic cirrus can significantly dehydrate and possibly denitrify upper troposphere air masses have been quantified in a single cloud simulation. However, a global quantification of these effects and its impact on the trace gas budget of the upper troposphere and lowermost stratosphere ultimately requires either a large number of such 1-D simulations similar to the statistical approach employed by Jensen and Pfister (2004) or truly three dimensional simulations.

It is possible that both small-scale dynamical forcings and heterogeneous ice nuclei modulate the cloud evolution. Lin et al. (2005) point out that the complex small-scale structure of weakly forced cirrostratus may entirely result from the action of ice nuclei when heterogeneous nucleation is assumed to be the dominant ice formation path. However, small-scale dynamical variability not included in their study will also contribute to the detailed cloud structure (Haag and Kärcher, 2004) so that the role of heterogeneous ice nucleation remains unclear.

Further, the present study shows that strong uptake of $\mathrm{HNO}_{3}$ in liquid aerosols may occur in cirrus conditions and that this process should be considered in the interpretation of field measurements. It would be interesting to examine the phase partitioning of $\mathrm{HNO}_{3}$ in the presence of cirrus ice crystals and ammonium in the background aerosol, as ammoniated sulfate particles are capable of dissolving greater amounts of $\mathrm{HNO}_{3}$ than STS particles under similar conditions. Field measurements point towards the presence of interstitial ammonium sulfate aerosols in polar cirrus (Petzold et al., 2000; Romakkaniemi et al., 2004). As a first step, an equilibrium study could help isolate parameter regions where enhanced dissolution of $\mathrm{HNO}_{3}$ in aerosols occurs, perhaps even in the presence of substantial amounts of cloud ice.
The present case study demonstrates that detailed comparisons with laboratory measurements of $\mathrm{HNO}_{3}$ uptake on growing ice and with suitable field data are required to better constrain open parameters of the trapping model. This will ultimately lead to a better understanding of the role of cirrus in determining the budget and vertical distribution of nitrogen oxides in the upper troposphere.

Finally, the existence of high supersaturations inside and nearby cirrus clouds at the cold tropopause has potentially important implications for heterogeneous halogen chemistry, as reaction rates on cold STS droplets and ice crystals are very large in such conditions (Kärcher and Solomon, 1999; Meilinger et al., 2001). The vertical distribution of ice crystal size spectra from detailed microphysical simulations of Arctic cirrus may help improve calculations of their radiative forcing.

\section{Appendix: Ice saturation relaxation timescale}

The goal is to derive an approximate expression for the relaxation time $\tau$ of $s_{i}=S_{i}-1$ valid for isothermal and isobaric conditions in order to compare it with numerical results shown in Fig. 4. Starting point is the balance equation for the ice saturation ratio $S_{i}$, as noted by Kärcher and Lohmann (2002):

$\frac{d S_{i}}{d t}=a_{1} w S_{i}-\left(a_{2}+a_{3} S_{i}\right) R$,

where $a_{1}, a_{2}, a_{3}$ are $p$ - and $T$-dependent constants (with $\left.a_{1} \sim 10^{-5} \mathrm{~cm}^{-1}\right), w$ is the vertical velocity, and $R$ is the depositional growth term

$R=4 \pi n_{i} r_{i} D_{w} \kappa_{i} \phi_{i} e_{i}\left(S_{i}-1\right)=a_{4}\left(S_{i}-1\right)$

in the diffusion limit which is mostly realized in this study. Here, $D_{w}$ is the diffusion coefficient for $\mathrm{H}_{2} \mathrm{O}$ molecules in air, $\kappa_{i}$ is the capacitance factor, $\phi_{i}$ the ventilation factor, and $e_{i}=1 / a_{2}$ is the $\mathrm{H}_{2} \mathrm{O}$ vapor number density at ice saturation. Only for small deposition coefficients $(<0.1)$ and/or very small ice crystals $(<1 \mu \mathrm{m}) R$ would scale in proportion to the cloud surface area density $A_{i}$.

Using the fact that $a_{3} S_{i}<a_{2}$, the balance equation can be cast into the form

$\frac{d s_{i}}{d t}=A+B s_{i}=A-\frac{s_{i}}{|\tau|}$,

where $A=a_{1} w$ and $B=a_{1} w-a_{2} a_{4}$. Growth during relaxation requires that $B<0$, viz.

$\tau=\frac{1}{4 \pi n_{i} r_{i} D \kappa_{i} \phi_{i}-a_{1} w}>0$.

The cooling term $a_{1} w$ is usually much smaller than the deposition term, implying that $\tau \propto 1 /\left(n_{i} r_{i}\right)$. The scatter of the numerical $\tau$-values shown in Fig. 4 is caused by the range of underlying growth conditions in the relaxation phase. 
Acknowledgements. This work was funded, in part, by the European Commission within the Integrated Project "StratosphereClimate Links With Emphasis on the UTLS" (SCOUT-O3). The author is grateful to C. Voigt, P. Popp, R.-S. Gao, D. Fahey, J. Hendricks, R.-F. Lin, J. Reichardt, F. Stroh, and T. Corti for scientific exchange and discussions.

Edited by: U. Pöschl

\section{References}

Abbatt, J. P. D., Beyer, K. D., Fucaloro, A. F., McMahon, J. R., Woolridge, P. J., Zhang, R., and Molina, M. J.: Interaction of $\mathrm{HCl}$ vapor with water-ice: Implications for the stratosphere, J. Geophys. Res., 97, 15 819-15 826, 1992.

Bartels-Rausch, T., Eichler, B., Zimmermann, P., Gäggeler, H. W., and Ammann, M.: The adsorption enthalpy of nitrogen oxides on crystalline ice, Atmos. Chem. Phys., 2, 235-247, 2002,

SRef-ID: 1680-7324/acp/2002-2-235.

Borrmann, S., Solomon, S., Dye, J. E., and Luo, B.: The potential of cirrus clouds for heterogeneous chlorine activation, Geophys. Res. Lett., 23, 2133-2136, 1996.

Curry, J., Rossow, W. B., Randall, W., and Schramm, J. L.: Overview of Arctic cloud and radiation characteristics, J. Clim., 9, 1731-1764, 1996.

Curry, J., Hobbs, P. V., King, M. D., Randall, D. A., Minnis, P., Isaac, G. A., Pinto, J. O., Uttal, T., Bucholtz, A., Cripe, D. G., Gerber, H., Fairall, C. W., Garrett, T. J., Hudson, J., Intrieri, J. M., Jakob, C., Jensen, T., Lawson, P., Marcotte, D., Nguyen, L., Pilewskie, P., Rangno, A., Rogers, D. C., Strawbridge, K. B., Valero, F. P. J., Williams, A. G., and Wylie, D.: FIRE Arctic Clouds Experiment, Bull. Amer. Meteorol. Soc., 81, 5-29, 2000.

Del Guasta, M., Morandi, M., Stefanutti, L., Stein, B., Kolenda, J., Rairoux, P., Wolf, J. P., Matthey, R., and Kyro, E.: Multiwavelength lidar observation of thin cirrus at the base of the Pinatubo stratospheric layer during the EASOE campaign, Geophys. Res. Lett., 21, 1339-1342, 1994.

Del Guasta, M., Morandi, M., Stefanutti, L., Balestri, S., Kyro, E., Rummukainen, M., Kivi, R., Rizi, V., Stein, B., Wedekind, C., Mielke, B. Matthey, R., Mitev, V., and Douard, M.: Lidar observations of spherical particles in a $-65^{\circ} \mathrm{C}$ cold cirrus observed above Sodankylä (Finland) during SESAME, J. Aerosol Sci., 29, 357-374, 1998.

Gao, R. S., Popp, P. J., Fahey, D. W., Marcy, T. P., Herman, R. L., Weinstock, E. M., Baumgardner, D. G., Garrett, T. J., Rosenlof, K. H., Thompson, T. L., Bui, T. P., Ridley, B. A., Wofsy, S. C., Toon, O. B., Tolbert, M. A., Kärcher, B., Peter, Th., Hudson, P. K., Weinheimer, A. J., and Heymsfield, A. J.: Evidence that ambient nitric acid increases relative humidity in low-temperature cirrus clouds, Science, 303, 516-520, 2004.

Haag, W., Kärcher, B., Schaefers, S., Stetzer, O., Möhler, O., Schurath, U., Krämer, M., and Schiller, C.: Numerical simulations of homogeneous freezing processes in the aerosol chamber AIDA, Atmos. Chem. Phys., 3, 195-210, 2003a,

\section{SRef-ID: 1680-7324/acp/2003-3-195.}

Haag, W., Kärcher, B., Ström, J., Minikin, A., Lohmann, U., Ovarlez, J., and Stohl, A.: Freezing thresholds and cirrus cloud formation mechanisms inferred from in situ measurements of relative humidity, Atmos. Chem. Phys., 3, 1791-1806, 2003b, SRef-ID: 1680-7324/acp/2003-3-1791.

Haag, W., and Kärcher, B.: The impact of aerosols and gravity waves on cirrus, clouds at midlatitudes, J. Geophys. Res., 109, D12202, doi:10.1029/2004JD004579, 2004.

Hallar, A. G., Avallone, L. M., Herman, R. L., Anderson, B. E., and Heymsfield, A. J.: Measurements of ice water content in tropopause region Arctic cirrus during SAGE III Ozone Loss and Validation Experiment (SOLVE), J. Geophys. Res., 109, D17203, doi:10.1029/2003JD004348, 2004.

Hanson, D. R.: The uptake of $\mathrm{HNO}_{3}$ onto ice, NAT, and frozen sulfuric acid, Geophys. Res. Lett., 19, 2063-2066, 1992.

Haynes, D. R., Tro, N. J., and George, S. M.: Condensation and evaporation of $\mathrm{H}_{2} \mathrm{O}$ on ice surfaces, J. Phys. Chem., 96, 85028509, 1992.

Huthwelker, T.: Experimente und Modellierung der Spurengasaufnahme in Eis, Ph.D. dissertation, Universität Bonn, Cuvillier Verlag, Göttingen, ISBN 3-89712-675-3, 1999.

Irie, H., Kondo, Y., Koike, M., Takegawa, N., Tabazadeh, A., Reeves, J. M., Sachse, G. W., Vay, S. A., Anderson, B. E., and Mahoney, M. J.: Liquid ternary aerosols of $\mathrm{HNO}_{3} / \mathrm{H}_{2} \mathrm{SO}_{4} / \mathrm{H}_{2} \mathrm{O}$ in the Arctic tropopause region, Geophys. Res. Lett., 31, L01105, doi:10.1029/2003GL018678, 2004

Jensen, E., and Pfister, L.: Transport and freeze-drying in the tropical tropopause layer, J. Geophys. Res., 109, D02207, doi:10.1029/2003JD004022, 2004.

Jensen, E., Pfister, L., Bui, T., Weinheimer, A., Weinstock E., Smith, J., Pittman, J., Baumgardner, D., Lawson, P., and McGill, M. J.: Formation of a tropopause cirrus layer observed over Florida during CRYSTAL-FACE, J. Geophys. Res., 110, D03208, doi:10.1029/2004JD004671, 2005a.

Jensen, E., Smith, J. B., Pfister, L., Pittman, J. V., Weinstock, E. M., Sayres, D. S., Herman, R. L., Troy, R. F., Rosenlof, K., Thompson, T. L., Fridlind, A. M., Hudson, P. K., Cziczo, D. J., Heymsfield, A. J., Schmitt, C., and Wilson, J. C.: Ice supersaturations exceeding $100 \%$ at the cold tropical tropopause: Implications for cirrus formation and dehydration, Atmos. Chem. Phys., 5, 851862,2005 ,

SRef-ID: 1680-7324/acp/2005-5-851.

Kärcher, B.: Simulating gas-aerosol-cirrus interactions: Processoriented microphysical model and applications, Atmos. Chem. Phys., 3, 1645-1664, 2003,

SRef-ID: 1680-7324/acp/2003-3-1645.

Kärcher, B. and Solomon, S.: On the composition and optical extinction of particles in the tropopause region, J. Geophys. Res. 104, 27 441-27 459, 1999.

Kärcher, B. and Lohmann, U.: A Parameterization of cirrus cloud formation: Homogeneous freezing of supercooled aerosols, J Geophys. Res., 107 (D2), doi:10.1029/2001JD000470, 2002.

Kärcher, B. and Haag, W.: Factors controlling upper tropospheric relative humidity, Ann. Geophys., 22, 705-715, 2004,

SRef-ID: 1432-0576/ag/2004-22-705.

Kärcher, B. and Basko, M. M.: Trapping of trace gases in growing ice crystals, J. Geophys. Res., 109, D22204, doi:10.1029/2004JD005254, 2004.

Kelly, K. K., Tuck, A. F., and Davies, T.: Wintertime asymmetry of upper tropospheric water between the Northern and Southern Hemispheres, Nature, 353, 244-247, 1991. 
Kondo, Y., Toon, O. B., Irie, H., Gamblin, B., Koike, M., Takegawa, N., Tolbert, M. A., Hudson, P. K., Viggiano, A. A., Avallone, L. M., Hallar, A. G., Anderson, B. E., Sachse, G. W., Vay, S. A., Hunton, D. E., Ballenthin, J. O., and Miller, T. M.: Uptake of reactive nitrogen on cirrus cloud particles in the upper troposphere and lowermost stratosphere, Geophys. Res. Lett., 30, 1154, doi:10.1029/2002GL016539, 2003.

Koop, T., Luo, B. P., Tsias, A., and Peter, Th.: Water activity as the determinant for homogeneous ice nucleation in aqueous solutions, Nature, 406, 611-614, 2000.

Lelieveld, J., Bregman, A., Scheeren, H. A., Ström, J., Carslaw, K. S., Fischer, H., Siegmund, P. C., and Arnold, F.: Chlorine activation and ozone destruction in the northern lowermost stratosphere, J. Geophys. Res., 104, 8201-8213, 1999.

Lin, R.-F., Starr, D. O'C., Reichardt, J., and DeMott, P. J.: Nucleation in synoptically forced cirrostratus, J. Geophys. Res., 110, D08208, doi:10.1029/2004JD005362, 2005.

Logan, J. A., Megretskaia, I. A., Miller, A. J., Tiao, G. C., Choi, D., Zhang, L., Stolarski, R. S., Labow, G. J., Hollandsworth, S. M., Bodeker, G. E., Claude, H., DeMuer, D., Kerr, J. B., Tarasick, D. W., Oltmans, S. J., Johnson, B., Schmidlin, F., Staehelin, J., Viatte, P., and Uchino, O.: Trends in the vertical distribution of ozone: A comparison of two analyses of ozonesone data, J. Geophys. Res., 104, 26373-26399, 1999.

Masuda, K., Kobayashi, T., Raschke, E., Albers, F., Koch, W., and Maixner, U.: Short-wave radiation flux divergence in Arctic cirrus: A case study, Atmos. Res., 53, 251-267, 2000.

Meilinger, S. K., Kärcher, B., von Kuhlmann, R., and Peter, Th.: On the impact of heterogeneous chemistry on ozone in the tropopause region, Geophys. Res. Lett., 28, 515-518, 2001.

Murphy, D. M., Kelly, K. K., Tuck, A. F., Proffitt, M. H., and Kinne, S.: Ice saturation at the tropopause observed from the ER-2 aircraft, Geophys. Res. Lett., 17, 353-356, 1990.

Murphy, D. M. and Koop, T.: Review of the vapour pressure of ice and supercooled water for atmospheric applications, Q. J. Roy. Meteor. Soc., 131, 1539-1565, 2005.

Nelson, J.: Interactive Comment on "Supersaturation, dehydration, and denitrification in Arctic cirrus", Atmos. Chem. Phys. Discuss., 5, S257-S260, 2005.

Petzold, A., Hoell, C., Kärcher, B., Beuermann, J., Schiller, C., Ziereis, H., and Schlager, H.: Observations of aerosols above ice saturation in the polar tropopause region, J. Geophys. Res., 105, 29387-29393, 2000.

Pfister, L., Selkirk, H. B., Jensen, E. J., Podolske, J., Sachse, G., Avery, M., Schoeberl, M. R., Mahoney, M. J., and Richard, E.: Processes controlling water vapor in the winter Arctic tropopause region, J. Geophys. Res., 108, 8314, doi:10.1029/2001JD001067, 2003.

Popp, P. J., Gao, R. S., Marcy, T. P., Fahey, D. W., Hudson, P. K., Thompson, T. L., Kärcher, B., Ridley, B. A., Weinheimer, A. J., Knapp, D. J., Montzka, D. D., Baumgardner, D. G., Garrett, T. J., Weinstock, E. M., Smith, J. B., Sayres, D. S., Pittman, J. V., Dhaniyala, S., Bui, T. P., and Mahoney, M. J.: Nitric acid uptake on subtropical cirrus cloud particles, J. Geophys. Res., 109, D06302, doi:10.1029/2003JD004255, 2004.

Reichardt, J., Reichardt, S., Behrendt, A., and McGee, T. J.: Correlations among the optical properties of cirrus cloud particles: Implications for spaceborne remote sensing, Geophys. Res. Lett., 29, doi:10.1029/2002GL014836, 2002.
Rogers, H., Teyssedre, H., Pitari, G., Grewe, V., Van Velthoven, P., and Sundet, J.: Model intercomparison of the transport of aircraft-like emissions from sub- and supersonic aircraft, Meterol. Z., 11, 151-159, 2002.

Romakkaniemi, S., Kokkola, H., Petzold, A., and Laaksonen, A.: Growth of upper tropospheric aerosols due to uptake of $\mathrm{HNO}_{3}$, Atmos. Chem. Phys., 4, 549-556, 2004,

SRef-ID: 1680-7324/acp/2004-4-549.

Rossow, W. B. and Schiffer, R. A.: Advances in understanding clouds from ISCCP, Bull. Amer. Meteorol. Soc., 80, 2261-2287, 1999.

Schiller, C., Afchine, A., Eicke, N., Feigl, C., Fischer, H., Giez, A., Konopka, P., Schlager, H., Tuitjer, F., Wienhold, F. G., and Zöger, $\mathrm{M}$ : Ice particle formation and sedimentation in the tropopause region: A case study based on in situ measurements of total water during POLSTAR 1997, Geophys. Res. Lett., 26, 2219-2222, 1999.

Schröder, F., Kärcher, B., Duroure, C., Ström, J., Petzold, A., Gayet, J.-F., Strauss, B., Wendling, P., and Borrmann, S.: On the transition of contrails into cirrus clouds, J. Atmos. Sci., 57, 464-480, 2000.

Smith, J. B., Hintsa, E. J., Allen, N. T., Stimpfle, R. M., Anderson, J. G.: Mechanisms for midlatitude ozone loss: Heterogeneous chemistry in the lowermost stratosphere?, J. Geophys. Res., 106, 1297-1309, 2001.

Solomon, S., Borrmann, S., Garcia, R. R., Portmann, R., Thomason, L., Poole, L. R., Winker, D., and McCormick, M. P.: Heterogeneous chlorine chemistry in the tropopause region, J. Geophys. Res., 102, 21 411-21 429, 1997.

Ström, J., Seifert, M., Kärcher, B., Ovarlez, J., Minikin, A., Gayet, J.-F., Krejci, R., Petzold, A., Auriol, F., Haag, W., Busen, R., Schumann, U., and Hansson, H.-C.: Cirrus cloud occurrence as a function of ambient relative humidity: A comparison of observations obtained during the INCA experiment, Atmos. Chem. Phys., 3, 1807-1816, 2003,

SRef-ID: 1680-7324/acp/2003-3-1807.

Thomas, A., Borrmann, S., Kiemle, C., Cairo, F., Volk, M., Beuermann, J., Lepuchov, B., Santacesaria, V., Matthey, R., Rudakov, V., Yushkov, V., MacKenzie, R. A., and Stefanutti, L.: In situ measurements of background aerosol and subvisible cirrus in the tropical tropopause region, J. Geophys. Res., 107, 4763, doi:10.1029/2001JD001385, 2002.

Thornton, B. F., Toohey, D. W., Avallone, L. M., Harder, H., Martinez, M., Simpas, J. B., Brune, W. H., and Avery, M. A.: In situ observations of $\mathrm{ClO}$ near the winter polar tropopause, J. Geophys. Res., 108, 8333, doi:10.1029/2002JD002839, 2003.

Ullerstam, M., Thornberry, T., and Abbatt, J. P. D.: Uptake of gasphase nitric acid to ice at low partial pressures: evidence for unsaturated surface coverage, Faraday Discuss., 130, in press, 2005.

Walcek, C. J.: Minor flux adjustment near mixing ratio extremes for a simplified yet highly accurate monotonic calculation of tracer advection, J. Geophys. Res., 105, 9335-9348, 2000.

Ziereis, H., Minikin, A., Schlager, H., Gayet, J.-F., Auriol, F., Stock, P., Baehr, J., Petzold, A., Schumann, U., Weinheimer, A., Ridley, B., and Ström, J.: Uptake of reactive nitrogen on cirrus cloud particles during INCA, Geophys. Res. Lett., 31, L05115, doi:10.1029/2003GL018794, 2004. 